\title{
Pseudo-Goodwin cycles in a Minsky model
}

Engelbert Stockhammer and Jo Michell

May 2014*

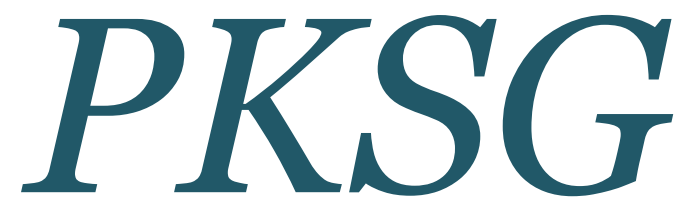

\section{Post Keynesian Economics Study Group}

Working Paper 1405

This paper may be downloaded free of charge from www.postkeynesian.net

2015 C Engelbert Stockhammer and Jo Michell

Users may download and/or print one copy to facilitate their private study or for non-commercial research and may forward the link to others for similar purposes. Users may not engage in further distribution of this material or use it for any profit-making activities or any other form of commercial gain.

* The paper was updated in February 2015. 


\title{
Pseudo-Goodwin cycles in a Minsky model
}

\begin{abstract}
Goodwin cycles result from the dynamic interaction between a profit-led demand regime and a reserve army effect in income distribution. The paper proposes the concept of a pseudoGoodwin cycle. We define this as a counter-clockwise movement in output and wage share space which is not generated by the usual Goodwin mechanism. In particular, it does not depend on a profit-led demand regime. As a demonstration, a simple Minsky model is extended by adding a reserve army distribution adjustment mechanism. The wage share responds positively to output but generates no feedback. In the augmented Minsky model, cycles are generated purely through the interaction between financial fragility and demand. By design, demand is not influenced by changes in income distribution. But the model does exhibit a pseudo-Goodwin cycle in the output-wage share space. This holds true even if a wage-led demand regime is introduced. This demonstrates that the existence of a counter-clockwise movement of output and the wage share cannot be regarded as proof of the existence of a Goodwin cycle and a profit-led demand regime.
\end{abstract}

Keywords: business cycles, Goodwin cycle, Minsky cycle, financial fragility, distribution cycles, Post Keynesian economics

JEL classifications: E11, E12, E32

Acknowledgements. The authors are grateful to Johannes Buchner, Sebastien Charles, Paulo dos Santos, Giorgos Galanis, Rob Jump, Javier Lopez, Nina Kaltenbrunner, Marc Lavoie, Maria Nikolaidi, Hiroshi Nishi and Peter Skott for comments. The usual disclaimers apply.

Engelbert Stockhammer

Kingston University

Engelbert Stockhammer, Kingston University, Penrhyn Road, KT1 2EE Surrey, UK

Email: e.stockhammer@kingston.ac.uk

Phone: +44 2084177774

Jo Michell, University of the West of England, Coldharbour Ln, Bristol BS16 1QY

Email: jo.michell@uwe.ac.uk 


\section{Introduction}

The question of how aggregate demand and income distribution interact to generate business cycles continues to generate considerable debate in the heterodox economics literature. One influential view is derived from Goodwin's (1967) model, in which the cycle is generated by the interaction between a profit-led demand function and a reserve army distribution function. The Goodwin cycle posits that an increase in the wage share will have a negative effect on demand because investment is driven by the profit share. At the same time, higher levels of output will result in a rising wage share due to the increased bargaining power of labour as unemployment falls. The interaction of these two elements generates a counter-clockwise cycle in output-wage share space.

There is a related, ongoing, debate about the nature of the demand regime in advanced economies. On one side are those who regard the demand regime as profit-led, in line with the assumptions of the Goodwin model (e.g. Taylor, 2012). On the other are those who argue that aggregate demand is wage-led (e.g. Stockhammer et al., 2009). These two strands of the literature intersect in studies which look for Goodwin-like patterns in empirical data and argue that such patterns provide support for the profit-led demand hypothesis: "A general finding is that 'profit squeeze' cycles exist for the US economy" (Barbosa-Filho \& Taylor, 2006, p. 392).

We take issue with this last claim, that the existence of a counter-clockwise movement in outputwage share space is proof of the existence of a Goodwin cycle and a profit-led demand regime. Instead, we demonstrate the existence of a pseudo-Goodwin cycle which we define as a counterclockwise movement in output and wage share space that is not generated by the standard Goodwin mechanism. Specifically, it does not rely on a profit-led demand regime - or indeed on any feedback from distribution to demand. Simply put, a pseudo-Goodwin cycle is something that looks like a Goodwin cycle but isn't.

To illustrate this we take a simple two equation predator-prey version of the Minsky model and add a distribution adjustment a la Marx and Goodwin. In Minsky's model, the cycle results from an interaction between financial and real variables. In its simplest version, the theory states that growing demand will give rise to higher debt ratios and that higher fragility will have a negative effect on demand. This will generate clockwise movements in output-fragility space.

In the Minsky model augmented with a reserve army effect, the wage share rises with higher levels of output. This model exhibits a pseudo-Goodwin cycle in output-wage share space. This cycle, however, is not a Goodwin cycle because - by design - there is no feedback from distribution to demand. Instead, the cycle is generated entirely by the interaction between financial fragility and demand. Further, we demonstrate that such pseudo-Goodwin cycles can still arise if we additionally assume a wage-led demand regime.

There have been some attempts at a synthesis of Goodwin and Minsky models (Keen 1995). These models have a feedback from distribution, as well as from finance, on aggregate demand. Our paper, however, is asking a different question. We are interested in a model that has a Minsky cycle and a reserve army effect, but no feedback from distribution to demand. We know, by design, that the business cycle in this model will be driven by the finance-demand interaction. What the literature 
has not so far analysed is the question of what cyclical properties such a system will exhibit in output-distribution space. In other words, we are asking what a researcher looking for a Goodwin cycle would see, if he encountered a Minsky world with a reserve army distribution function.

The main purpose of the paper is one of theoretical clarification. The models presented are highly stylized. We use predator-prey models which generate stable cycles and, for the sake of clarity, we keep the number of parameters to a minimum. The baseline Goodwin and Minsky models on which we build generate stable cycles (closed orbits). We investigate the stability of the extended Minsky models, but our main concern is to establish the direction in which the cycle turns in output-wage share space.

The paper is structured as follows. Section 2 presents a benchmark Goodwin model and discusses the related literature. Section 3 presents a simple Minsky model. Section 4 introduces a distribution function with a reserve army effect into the Minsky model and demonstrates the existence of pseudo-Goodwin cycles. Section 5 introduces a weak wage-led effect in the demand function. Section 6 concludes.

\section{The Goodwin cycle}

Goodwin $(1967,1972)$ presents a simple dynamic model of the cyclical interaction of the growth rates of employment and income distribution based on two key Marxian relationships. The first is the reserve army assumption that as unemployment increases the bargaining power of labour is diminished, leading to a fall in the wage rate. This implies a relationship in which higher levels of output are associated with higher employment and a rising wage share. The second is the profit squeeze theory of accumulation which holds that output growth is constrained by higher real wage rates because investment is driven by profits - so that, as wages rise and profits fall, investment is curtailed and the rate of growth falls.

These two relationships can be combined to give the following system of differential equations in which $y$ represents output and $w$ the wage share, all parameters are positive, and $\dot{y}$ and $\dot{w}$ signify the derivatives of each variable with respect to time:

$\dot{y}=y(1-w)$

$w=w(-c+r y)$

The first equation captures the profit squeeze theory and the second the reserve army effect. A number of simplifying modifications are made to the original Goodwin model. In particular, in the original model, it is assumed that labour productivity and the labour force grow at a steady exogenous rate while in our formulation we assume constant labour productivity. Our model thus generates cycles in output around the steady state, while the original Goodwin model is a growth model. We have also replaced employment (as in the original model) with output. Since Goodwin assumes constant labour productivity and an elastic supply of labour this makes no difference to the logic of the model. 
The pair of equations is analogous to the Lotka-Volterra biological model of the dynamic interaction of the populations of two species: a predator and a prey (Lotka 1925, Volterra 1926). In the LotkaVolterra model, higher populations of the prey species allow the predator population to grow. The increasing predator population eventually overwhelms the supply of prey, leading to a fall in the prey population and, eventually, in the predator population. The interaction of the two species generates the cyclical dynamics of the Lotka-Volterra system. In Goodwin's version, the prey variable is employment, which increases when output rises. The predator variable is the wage share since, according to the profit squeeze theory, a higher wage rate reduces profits and thus causes a fall in investment and growth.

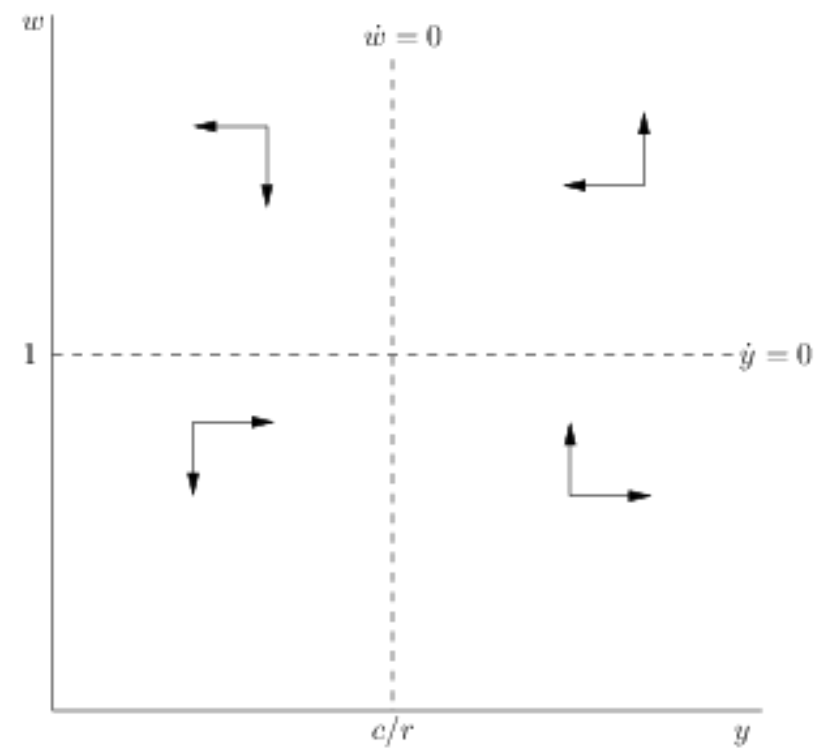

Figure 1. Phase diagram for the Goodwin Model

The Goodwin system specified in equations (1) and (2) has two stationary points, the first where both variables are equal to zero, and the second at, $y^{*}=\frac{c}{r}, w^{*}=1$

The first stationary point can be shown to be an unstable saddle-point, while the second is the centre of a family of concentric closed orbits. The shapes of the orbits are defined by the parameters of the model, while the specific orbit generated by the system is determined by the starting values of the variables. The phase diagram for the model is shown in Figure 1 and the Jacobian matrix of the system evaluated at the non-zero stationary point can be calculated as the following,

$I=\left[\begin{array}{cc}0 & -\frac{c}{r} \\ r & 0\end{array}\right]=\left[\begin{array}{cc}0 & - \\ + & 0\end{array}\right]$

The non-zero stationary point occurs at the intersection of the two nullclines of the system: $y=\frac{c}{r}$ and $w=1$. The direction of rotation around this point is determined by the signs of the two 
coefficients. In the current system, the direction of rotation is counter-clockwise in $(y, w)$ space: output peaks before the wage share. ${ }^{1}$

It should be noted that - as in Goodwin's original - our model is specified so that the wage share is not bounded and, in particular, may exceed unity. We have chosen this specification for the sake of simplicity. As shown by Desai et. al (2006), replacing the linear functions of the Goodwin model with suitable non-linear alternatives transforms the model so that employment rates and the wage share remain within the range $(0,1)$. While we use the linear version of the model for the sake of clarity, this means that the absolute values of variables should not be seen as meaningful - our primary interest is in the dynamics of motion. In Appendix A.4 we present more complex versions of the models in which the wage share is constrained to remain below unity.

In this and subsequent models we normalise some parameters in order to reduce mathematical complexity. ${ }^{2}$ Figure 2 shows the result of simulating this pair of equations with parameter values of $c=0.9$ and $r=0.95$ and starting values, $y=0.7, w=0.7$. The system generates an anticlockwise cycle in $(y, w)$ space as shown in the bottom pane. The top pane plots each variable against time, illustrating that peaks in output precede peaks in the wage share.

The Goodwin model has given rise to a rich literature. This comprises both more elaborate cyclical models (e.g. Skott 1989, Shah and Desai 1981) and empirical research which either looks for the existence of Goodwin-like patterns in historical data or estimates the behavioural relationships of cyclical models.

${ }^{2}$ An equation of the form $y=y(a-p w)$ is replaced with $y=(1-w)$ by fixing $a=p=1$. Parameter values fix the centre of the cycle and shape of the trajectories but do not affect the qualitative behaviour of the system. 


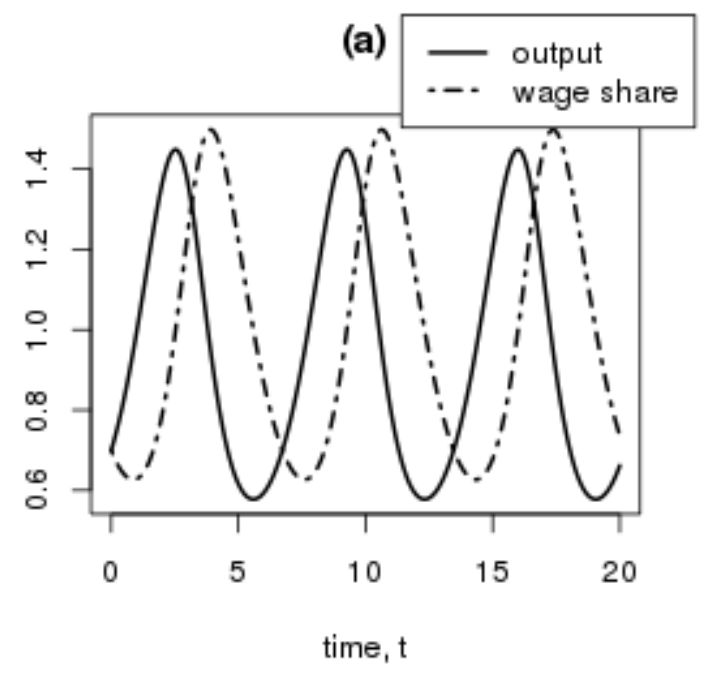

(b)

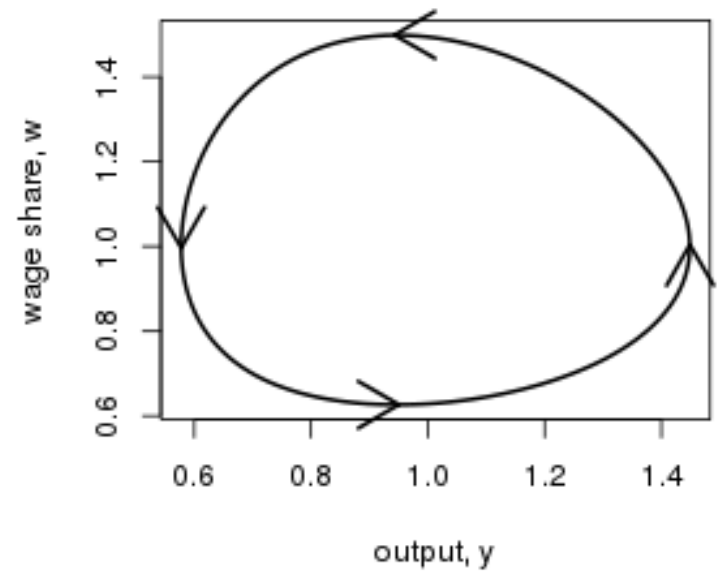

Figure 2. A simulation of the Goodwin model

An early debate in the Marxian literature focused on the mechanisms driving post-war US business cycles. One side of the debate followed Goodwin in arguing the upper turning point arises from a profit squeeze due to rising wages (e.g. Goldstein, 1999a, 1999b, 2002). The other argued that insufficient aggregate demand is the primary cause of downturns (e.g. Sherman, 1997, Van Lear 1999).

More recently, there has been debate among those inspired by the Goodwin literature and those who emphasise the role of aggregate demand. The followers of Goodwin argue that graphical plots of the wage share and unemployment show counter-clockwise patterns consistent with the dynamics of the Goodwin model. 
This literature distinguishes between long-run and short-run cycles. Solow (1990) examines the data and concludes that there is very weak evidence for long-run Goodwin cycles. Flaschel et. al. (2010), update previous research by Flaschel and Groh (1995) and examine data for eight OECD countries, concluding there is strong evidence for a long-run Goodwin cycle. Veneziani and Mohun (2006) argue that such long-run cycles are theoretically problematic and the empirical trends are more likely to be driven by structural change. The evidence for shorter-run (10-15 years) Goodwin cycles appears stronger. Desai (1984) presents evidence of such cycles in the post-war UK. Harvie (2000) examines data from 10 OECD countries, finding evidence of incomplete (approximately threequarter-length) Goodwin cycles in most of the countries examined. Mohun and Veneziani (2008) find strong evidence for short-run Goodwin cycles in the post-war US data.

The other stream of empirical literature, often inspired by the works of Kalecki, is based on econometric estimation of behavioural macroeconomic relationships such as investment and consumption functions. Depending on the relative elasticities of demand with respect to income distribution and profit rates, regimes can be classified as either wage-led or profit-led. The connection with the Goodwin model stems from Goodwin's assumption of a profit-led regime - a wage-led regime will not, in general, generate anti-clockwise cycles. Hein and Vogel (2008), Naastepad and Storm (2006), Onaran and Galanis (2012), Stockhammer et al (2009), and Stockhammer and Stehrer (2011) estimate consumption, investment and net export equations and find that aggregate demand is wage-led in many countries. On the other hand, Barbosa-Filho and Taylor (2006) and Flaschel and Proano (2007) estimate demand and distribution equations and find evidence that demand in the USA is profit-led. ${ }^{3}$ Kiefer and Rada (2014) do so for a panel of OECD countries with a set of control variables that shift income distribution and find that demand is profit led.

A recent contribution by Taylor (2012) connects the theoretical and empirical strands. Taylor contrasts two models of distribution and demand. The first combines a locally stable "Domar-style" investment function (that leads to a profit-led regime) with a Goodwin-type reserve-army distribution function. This is contrasted with a model which combines an unstable "Harrod-style" investment function (which produces a wage-led demand regime) with a distribution function based on a pro-cyclical profit-share. The first model generates Goodwin-type counter-clockwise cycles in output-distribution space, while the second generates cycles which turn in the opposite direction. On the basis of the empirical evidence, Taylor argues that the anticlockwise Goodwin-type movement is what is being observed. He concludes, "Overall, Domar-style investment and a profit squeeze appear to fit the data better than Harrod and short-run wage-led aggregate demand" ( $p$. 50). Taylor thus cites the apparent existence of counter-clockwise cycles in the empirical data as

\footnotetext{
${ }^{3}$ Barbosa-Filho and Taylor (2006) estimate a two equation VAR with a demand equation and a distribution equation for the US economy using quarterly data and the cyclical component of the HP filter. The effects for individual components of demand are then decomposed from the aggregate results (rather than estimated as behavioural equations). This gives a strongly profit-driven consumption function. Since the (negative) effect of an increase in the wage share on consumption outweighs the combined positive effect on investment and net exports, they conclude that the US economy is a profit-led system. However, their results for consumption and investment are inconsistent with the Goodwin model.
} 
evidence for a Goodwin mechanism and a profit-led demand regime. A similar approach is taken by Diallo et al (2011) who construct a model with four possible regimes: clockwise and counterclockwise cyclical regimes, and two saddle-point cases which do not generate cyclical behaviour. Diallo et al (2011) also conclude that the empirical evidence supports the profit-led version of the model.

Taylor extends the analysis by discussing models where cyclical behaviour is generated by the interaction of financial variables and demand in a Minskian framework in which asset prices and debt interact. However, these financial models are left only partially specified. In particular, the role of income distribution is not investigated, thus the question what type of cycles the financial group of models gives rise to in the wage share-income space is not investigated.

It is this question that we consider in the remainder of the paper. In particular, we take issue with the claim that finding something that looks like Goodwin cycles in the data implies that the mechanism generating those cycles is a profit-led demand regime. We demonstrate that such cycles can instead be generated by the interaction of financial fragility, demand and distribution. In particular, models can be constructed which generate Goodwin-type cycles but do not rely on a profit-led demand function.

\section{A Minsky cycle}

Unlike the Goodwin model, there is no canonical version of the Minsky cycle. Minsky's own work (Minsky 1975, 1986) presents a verbal description of the cycle mechanism, but no formal model. Consequently, several different models purporting to summarise his argument have been proposed (e.g. Skott 1994, Asada 2001, Fazzari et al 2008, Charles 2008). For our purposes, however, the basic structure of the argument is clear enough. The cycle results from the interaction of goods market demand and financial fragility of non-financial businesses.

This section will present only a minimalistic version of the Minsky model - the main aim of the paper is to investigate the properties of the model when it is extended to include a reserve army function. To ensure comparability with the structure of the Goodwin we also use a predator-prey model.

The model consists of two differential equations:

$\dot{f}=f(-1+p y)$

$\dot{y}=y(1-f)$

Equation (3) specifies the rate of increase of financial fragility, $f$, as a positive function of the level of demand. The assertion is that during a boom firms adopt a progressively more optimistic outlook and therefore take on higher levels of debt (relative to revenue) - financial fragility is usually thought of as the inverse of the debt-to-income ratio of firms. Banks share the optimistic outlook and are increasingly willing to lend as the boom progresses. The balance sheets of economic units in the Minsky model endogenously become more fragile at higher levels of output. 
Equation (4) specifies an inverse relationship between aggregate demand growth and the degree of fragility of the system. This is because the degree of indebtedness of firms makes them vulnerable to bankruptcy once interest rates rise and/or a larger share of cash flows is absorbed by debt services, which negatively impacts on investment. Skott (1994), Asada (2001), Fazzari et al (2008), and Charles (2008) derive such models from behavioural functions and discuss them further.

Our formulation captures Minsky's basic argument while sidestepping a number of controversies surrounding his model. The source of disagreement in the literature is twofold. Firstly, there is no consensus on the mechanism which generates the negative feedback from financial fragility to demand. In Fazzari et al (2008) this is due to the effect of the central bank increasing interest rates in response to rising inflation at the peak of the cycle. Much of the literature, however, argues that the increasing debt ratio of firms eventually leads commercial banks to increase interest rates, thereby causing the downturn (e.g. Charles 2008). Second, while Minsky regarded the upswing as being accompanied by an increasing leverage ratio of firms, Lavoie and Seccareccia (2001) have demonstrated that Minsky's argument is based on microeconomic principles that need not hold in the Kaleckian macroeconomic framework that Minsky is assuming (see also Michell, 2014). Given the Kaleckian assumption that workers do not save out of wage income, aggregate profits at the macroeconomic level are determined by the investment of firms. In such a framework, it is not clear why the debt ratio should rise during the boom. Rather, the high rate of investment growth during the boom should be expected to lead to decreasing leverage ratios.

Our model avoids both issues by design. First, Equation 3 states that financial fragility increases with output. We thus follow Minsky's argument of a pro-cyclical leverage ratio, otherwise no cycle in output and financial fragility would arise. Second, Equation 4 does not specify what brings about the rise in interest rates. Rather it simply posits that higher fragility leads to lower growth of demand.

The non-trivial steady state solution of the Minsky model is

$f^{*}=1, y^{*}=\frac{1}{p}$

and the Jacobian at the steady state is

$I=\left[\begin{array}{cc}0 & p \\ -\frac{1}{p} & 0\end{array}\right]=\left[\begin{array}{ll}0 & + \\ - & 0\end{array}\right]$ 


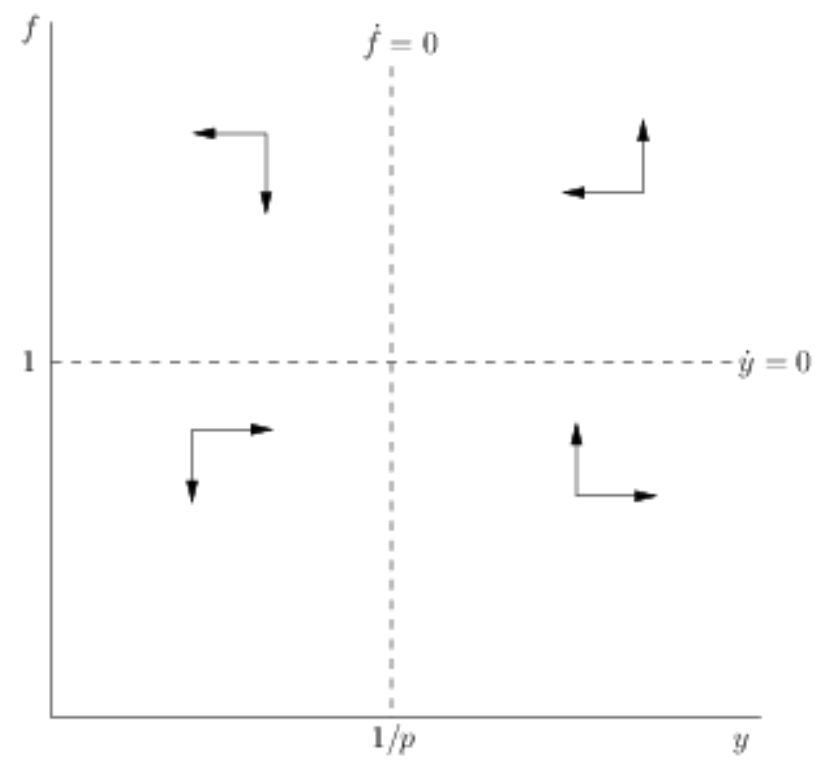

Figure 3 Phase diagram for Minsky model

Figure 4 simulates the dynamics of the system with $p=0.95$ and initial values $y=0.7, f=0.7$. The system generates cycles such that peaks in output precede peaks in financial fragility (Figure 2a). Alternatively, this could be expressed by saying that the system produces anti-clockwise motion in output-fragility space (clockwise motion in fragility-output space) (Figure $4 b$ ).

(a)

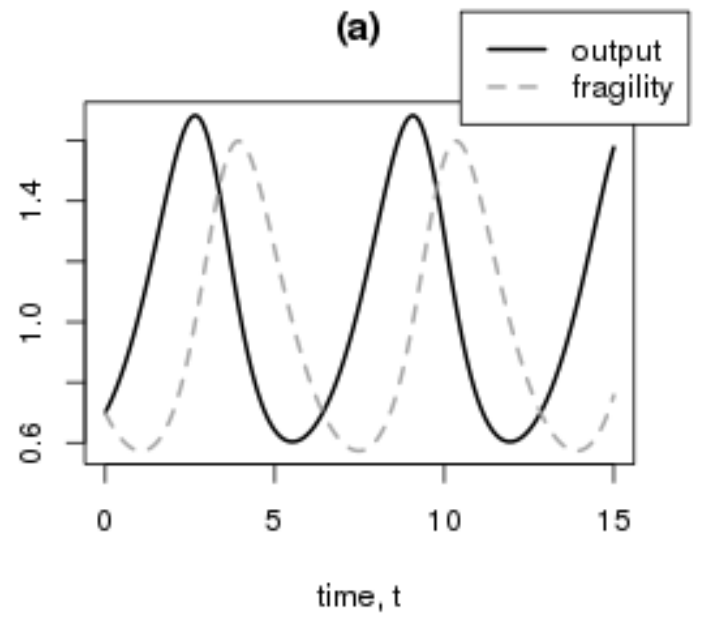

(b)

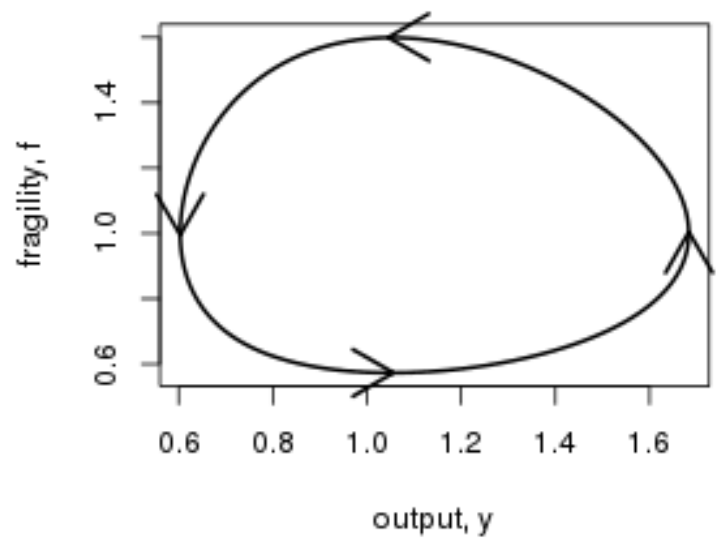

Figure 4 Simulation of Minsky model

\section{A Minsky cycle with a reserve army effect}


In this section we discuss a Minsky model that includes a reserve army effect. The dynamics of this system will be driven entirely by the interaction between financial fragility and demand. The distribution function has, by design, no feedback on demand. We retain equations 3 and 4 . To this we add a distribution equation with a reserve army effect:

$\dot{w}=w(-c+r y-w)$

This equation is similar to Equation (2), but additionally includes a negative feedback effect upon itself. This feedback term places an upper limit on the wage share. It may be interpreted as representing mechanisms which counteract workers' wage demands. These mechanisms become progressively stronger at higher real wages. The mathematical formulation is equivalent to what is known as the logistic equation in biology. In the context of population dynamics, the logistic equation imposes an upper bound on the population due to the carrying capacity of the environment (Nolting et al 2008).

The distribution of income has no feedback onto the other variables of the system: it is auxiliary to the cyclical dynamics of the system which are fully determined by the interaction between $f$ and $y$. In the language of biological models distribution is a scavenger: its population growth depends on the population of another species, but the causality is unidirectional (Chauvet et al 2002, Nolting et al 2008). ${ }^{4}$

This model may appear similar to models that try to integrate Goodwin and Minsky mechanisms, such as Keen (1995). However, there is an important difference in terms of the synthesis as well as in terms of the questions these models are supposed to answer. Keen (1995) constructs a model with the intention of examining the properties of models which have feedbacks from both distribution and finance to aggregate demand. Causality thus runs from both demand and distribution to finance and vice versa. We are asking a different question. We are interested (in this section) in a model that has a Minsky cycle and a Marxian distribution function but has no feedback from distribution to demand. ${ }^{5}$ We subsequently extend the analysis to allow for feedback from distribution to demand.

The interior steady state of the model occurs at the following point:

$f^{*}=1, y^{*}=\frac{1}{p}, w^{*}=-c+\frac{r}{p}$.

\footnotetext{
${ }^{4}$ Strictly speaking a scavenger population depends on deaths of prey, i.e. the kill rate. Our wage share depends on the population of output rather than its death rate. Biologically speaking distribution thus plays the role of a harmless parasite rather than a scavenger.

${ }^{5}$ We are bypassing the issue of whether income distribution can have an effect on financial fragility. As in other post-Keynesian models, changes in the wage share have conflicting effects on aggregate demand because they affect consumption and investment in opposite directions. Retained (realised) profits will affect financial fragility if it is defined as the debt to income ratio of business. An exploration of this interesting issue is beyond the scope of this paper.
} 
The dynamics of the model are simulated with parameters $c=1, p=0.95, r=1.6$ and starting values of $f=0.7, y=0.7, w=0.8$. The model generates oscillations in all three variables (Figure 5a). Peaks in output precede those in fragility and the wage share. As in the pure Minsky model, the cycle that drives the system is generated by the interaction between fragility and demand (Figure $5 b$; a formal analysis of stability conditions is delegated to Appendix A.1).

The key feature of this system is that it generates limit cycles in $y$ and $w$ that look like a Goodwin cycle (Figure 5c). This cycle, however, is simply a side effect of the cycle generated by the interaction of financial fragility and demand. We call this a pseudo-Goodwin cycle: a counter-clockwise rotation in $y, w$ space that is not due to the mechanisms of the original Goodwin model. ${ }^{6}$ The model also generates cycles in distribution and fragility. Like the pseudo-Goodwin cycles these do not arise out of direct causal links between these variables but as side effects of other causal relations.

If Equation (5) is replaced with Equation (2) so that the wage share is not bounded, the system will still exhibit pseudo-Goodwin cycles - anticlockwise oscillations in $(y, w)$ space. The model will, however, in general not generate limit cycles in $(y, w)$ space. ${ }^{7}$ Instead, we obtain either dampened or explosive oscillations in distribution. The behaviour of the system is determined by the value of $\frac{1}{p}-\frac{c}{r}$. If this expression is negative, the system generates damped oscillations in $w$ so that the wage share eventually falls to zero. Intuitively this corresponds to a case in which falls in the wage share during recessions exceed increases during booms so that the wage share exhibits a secular declining trend. In the case that $\frac{1}{p}-\frac{\sigma}{r}$ is positive we get oscillations with increasing amplitude. Intuitively this represents a case in which the wage share rises further during booms than it falls during recessions, resulting in a tendency towards a long-run increase in the wage share.

\footnotetext{
${ }^{6}$ To illustrate that there is no true Goodwin cycle in the model, assume that $f$ is fixed. If $f>1$ then both $y$ and $w$ will increase exponentially without fluctuations. If $f<1$ then both $y$ and $w$ will collapse to zero, again without fluctuations. In isolation from $f$, the equations for $y$ and $w$ cannot generate a cycle. Thus, when the full three-variable system exhibits cycles in the wage share-output space, it is not a Goodwin cycle. However, in the absence of evidence of the role played by $f$, the cycle in output and distribution could be interpreted as arising out of direct Goodwin-type interaction between the two variables.
}

${ }^{7}$ A closed orbit in distribution and output is possible if $\frac{1}{p}-\frac{e}{r}=0$. 


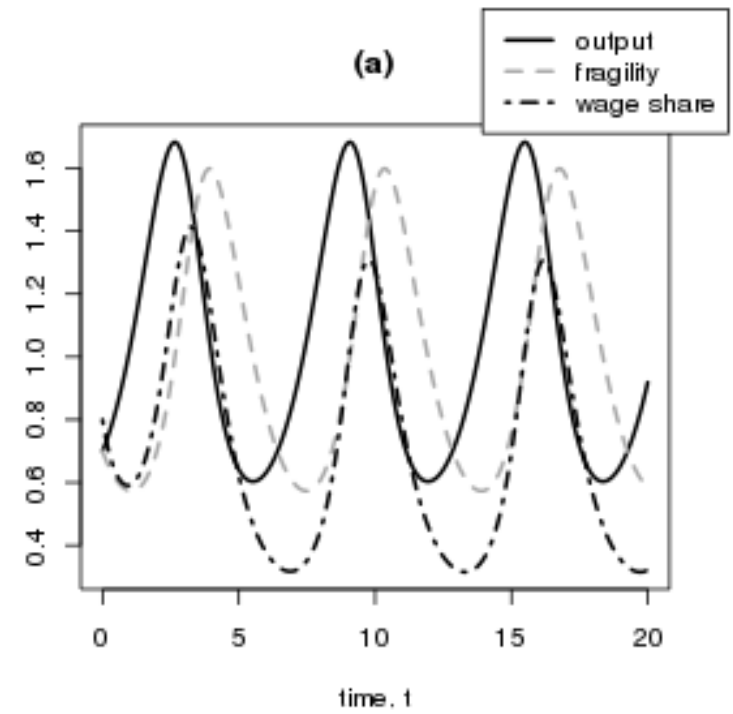

(c)

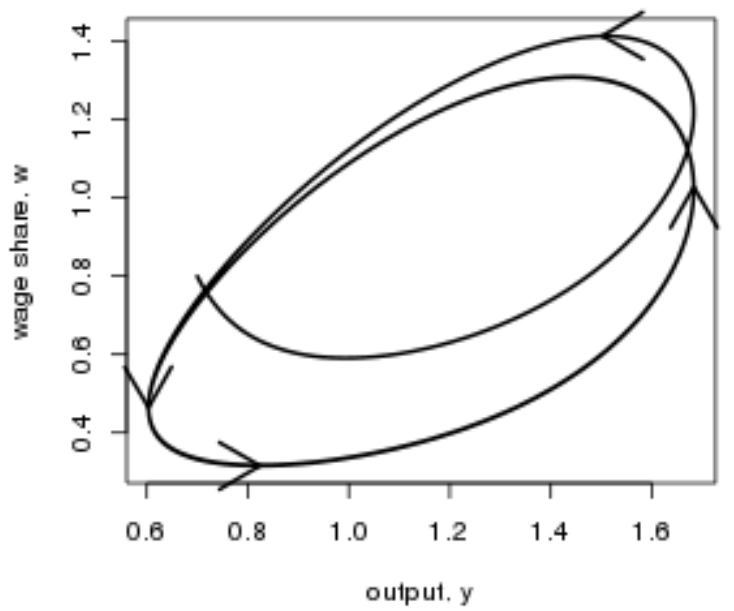

(b)

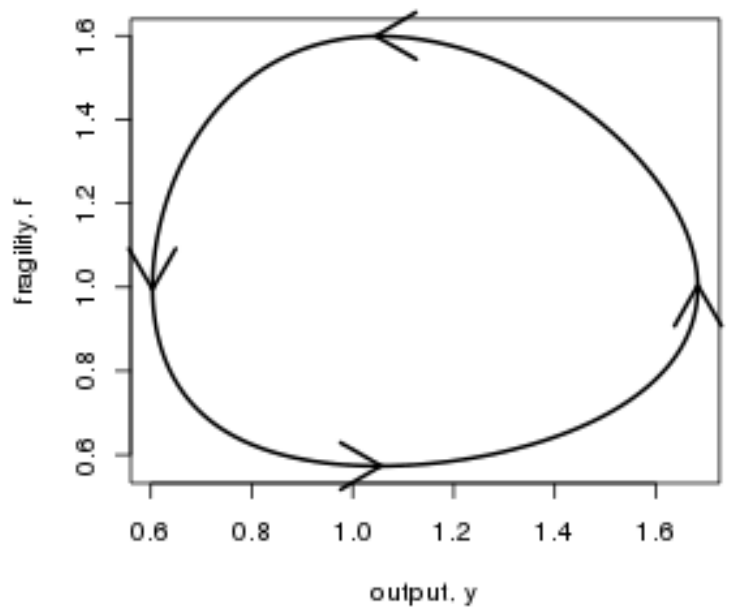

(d)

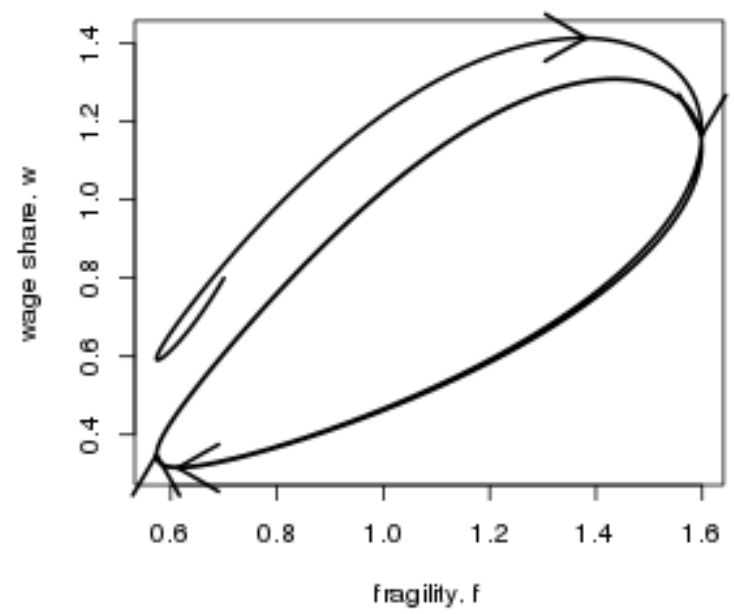

Figure 5 Simulation of the augmented Minsky model

\section{A Minsky model with distribution function and a wage-led effect in the demand function}

The previous section demonstrates that pseudo-Goodwin cycles can arise in a system in which income distribution has no influence on demand. In this section we introduce one more ingredient into our model: a positive feedback from the wage share to output. In other words, we investigate whether a pseudo-Goodwin cycle can arise in wage-led economy.

To do so, we retain equations ( 3 ) and (5) but replace Equation (4) with Equation (4a), which includes a positive feedback from the wage share to demand.

$\dot{y}=y(1-f+s w)$ 
The interior steady state solution of this system is:

$$
y^{*}=\frac{1}{p}, f^{*}=1+s\left(-c+\frac{r}{p}\right), w^{*}=-c+\frac{r}{p} \text {. }
$$

The dynamics of this system are depicted in Figure 6, assuming parameter values of $c=1, p=0.95, r=1.6, s=0.02$ and starting values $f=0.7, y=0.7, w=0.8$. The cyclical behaviour of the model is still driven by the interaction between $y$ and $f$ (Figure $6 \mathrm{~b}$ ). However, this no longer produces a closed orbit because of the instability introduced by the wage-led demand term (for a proof of the existence of explosive cycles see Appendix A.3). As before, if $f$ were fixed, the system in (4') and (5) would exhibit explosive non-oscillatory growth: the feedback from distribution to output as well as from output to distribution are positive.

Figure $6 \mathrm{c}$ shows that our model still exhibits the key feature of a pseudo-Goodwin cycle - counterclockwise motion in output-wage share space. However this cyclical motion is now unstable, so that outward spirals are generated in the phase space of all three pairs of variables.

The introduction of a wage-led demand function into the system thus does not prevent the generation of pseudo-Goodwin cycles. Instead it simply switches the system from generating limit cycles to unstable oscillations. Evidence of counter-clockwise motion in output-wage-share space thus does not provide sufficient evidence to rule out a wage-led demand regime. 


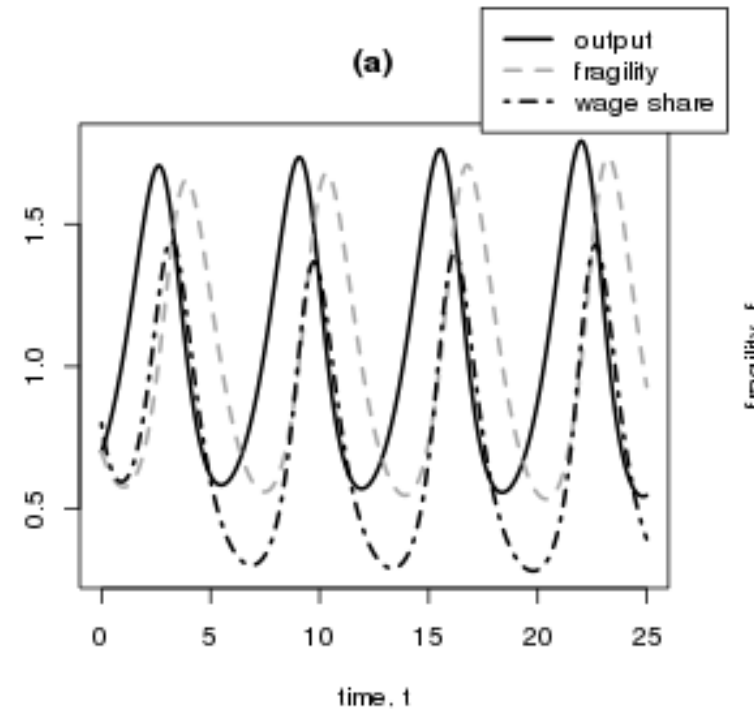

(c)

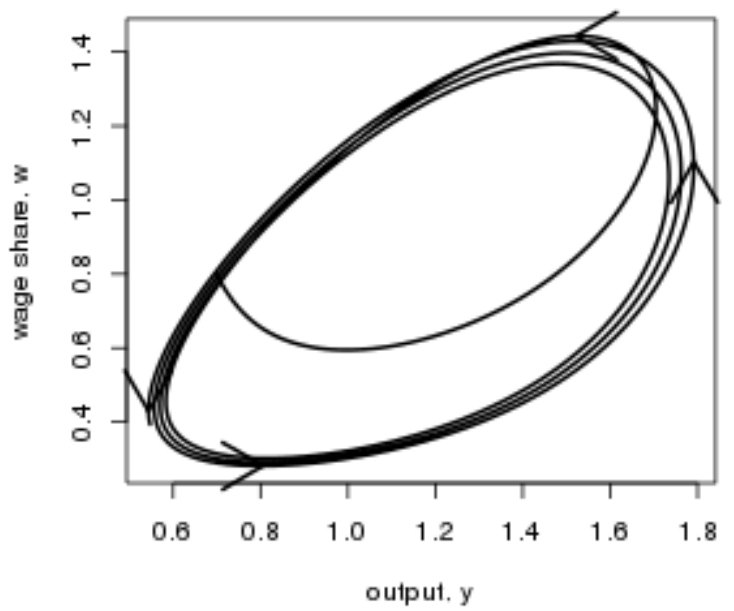

(b)

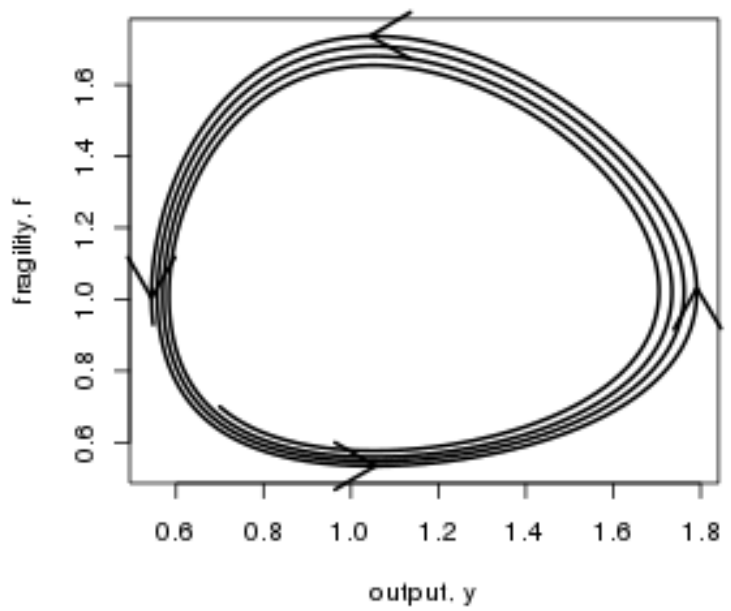

(d)

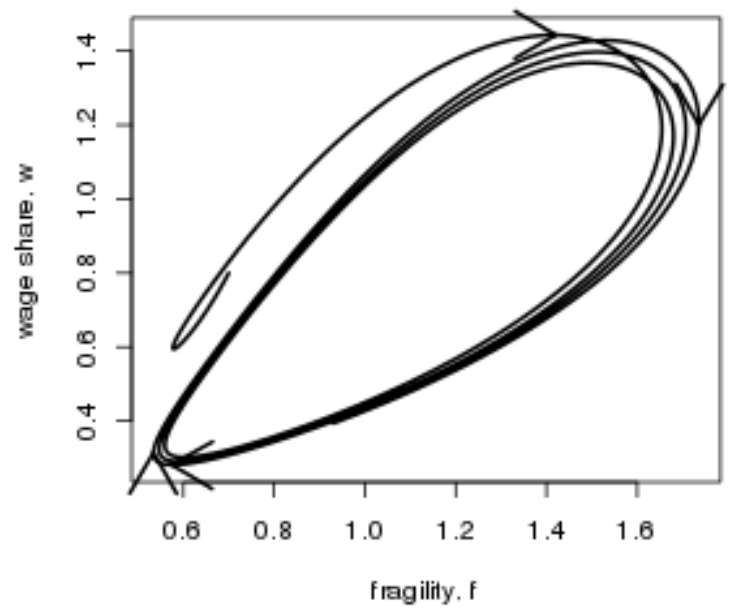

Figure 6 Simulation of Pseudo-Goodwin model with wage-led demand.

Since this system is explosive, several remarks may be useful. First, the model specification does not impose bounds on the wage share. Since the wage share is increasing it would eventually hit an upper bound at which point the dynamics of the system would change. Our finding is therefore that the model will exhibit pseudo-Goodwin cycles as long the wage share remains below this upper bound. Second, there is the question how to interpret an explosive system of this type. The model is a highly stylized wage-led Minsky model. In the analysis of Minsky as well as of Kalecki there is nothing that imposes long-run stability on the system. Both authors emphasised mechanisms in an unregulated market system that would give rise to instability and both argued that ultimately government intervention was needed to stabilise the system. Third, the model is a very simple one. Over longer time periods and sufficiently far from the steady state one would expect parameters to 
change. For example, government behaviour may change in reaction to prolonged depression or an explosive boom. Modelling these mechanisms is, however, beyond the scope of this paper.

\section{Conclusion}

Goodwin's (1967) model generates counter-clockwise cycles in output-wage-share space due to the interaction of a profit-led demand regime and a reserve army distribution function. The paper has demonstrated that counter-clockwise cycles in output-wage-share space can arise for reasons that are unrelated to the Goodwin mechanisms. We call such counter-clockwise cycles that are not based on a profit-led demand regime pseudo-Goodwin cycles. As an illustration, a Minsky model of the interaction of financial fragility and output is extended to include a reserve army function. In a second step we introduce a wage-led effect in the demand equation. In both cases we show that pseudo-Goodwin cycles can arise.

This lends itself to the following conclusions. First, any cycle that is not based on feedbacks from income distribution can produce pseudo-Goodwin cycles if the wage share adjustment is a la Marx and Goodwin. Second, the existence of a counter-clockwise movement of in output wage share space is not a sufficient condition for the existence of actual Goodwin cycles and can therefore not be interpreted as evidence in supporting the existence of a profit-led demand regime. Indeed a wage-led demand regime can be perfectly consistent with pseudo-Goodwin cycles.

\section{References}

Asada, T. 2001 Nonlinear dynamics of debt and capital: a Post-Keynesian analysis. In Y. Aruka (Ed.) Evolutionary Controversies in Economics (Tokyo: Springer-Verlag).

Barbosa-Filho, N., and L. Taylor 2006. Distributive and demand cycles in the US economy -a structuralist Goodwin model. Metroeconomica 57, (3): 389-411

Charles, Sebastien, 2008. Teaching Minsky's financial instability hypothesis: a manageable suggestion. Journal of Post Keynesian Economics 31, 1: 125-38

Chauvet, E., Paullet, J., Previte, J. and Walls, Z., 2002. A Lotka Volterra three-species food chain. Mathematics Magazine 75, 4: 253-55

Desai, M. 1984. An econometric model of the share of wages in national income: UK 1855-1965. In R. M. Goodwin (Ed.) Non-linear models of fluctuating growth, (pp. 253-77). Berlin: Springer.

Desai, M., Henry, P., Mosley, A. and Pemberton, M., 2006. A clarification of the Goodwin model of the growth cycle. Journal of Economic Dynamics and Control, 30, pp. 2661-2670.

Diallo, M., Flaschel, P., Krolzig, H. and Proaño, C., 2011. Reconsidering the Dynamic Interaction between Real Wages and Macroeconomic Activity. Research in World Economy. 2, 1, 77-93 
Fazzari, S., Ferri, P. and Greenberg, E., 2008. Cash flow, investment, and Keynes-Minsky cycles. Journal of Economic Behavior \& Organization, 65, 3-4, 555-572

Flashel, P., \& Groh, G. 1995. The classical growth cycle: reformulation, simulation and some facts. Economic Notes, 24, 293-326.

Flaschel, P. , G. Groh, G. Kauermann and T. Teuber 2010. The Goodwin Distributive Cycle After Fifteen Years of New Observations, in Flaschel, P. (ed.), Topics in Classical Micro- and Macroeconomics, Springer Berlin Heidelberg

Flaschel, P. and C. Proano 2007. AS-AD Disequilibrium dynamics and the Taylor interest rate policy rule: Euro-Area based estimation and simulation. In: Aspects of Modern Monetary and Macroeconomic Policies. Ed. P. Arestis, E. Hein and E. Le Heron. Houndsmill: Palgrave MacMillan Goldstein, J. P. 1999a. Predator-Prey Model Estimates of the Cyclical Profit Squeeze. Metroeconomica 50, 2, pp. 139-173.

Goldstein, J.P. 1999b. The simple analytics and empirics of the cyclical profit squeeze and cyclical underconsumption theories: clearing the air. Review of Radical Political Economics, 1999, 31(2), pp. $74-88$

Goldstein, J. P. 2002. The profit squeeze is supported by the PW cycle indicator. Review of Radical Political Economics, 34, 75-77.Goodwin, R.M., 1967, A Growth Cycle, in C.H. Feinstein (ed.), Socialism, Capitalism and Economic Growth. Cambridge: Cambridge University Press.

Goodwin, R.M., 1967 A Growth Cycle, in C.H. Feinstein, editor, Socialism, Capitalism and Economic Growth. Cambridge: Cambridge University Press

Goodwin, R.M., 1972, A Growth Cycle, in Hunt, E.K. and Schwartz, J.G. (eds.), A Critique of Economic Theory. Harmondsworth: Penguin (revised version of Goodwin, 1967)

Harvie, D. 2000. Testing Goodwin: growth cycles in ten OECD economies. Cambridge Journal of Economics 24: 349-76

Hein, E., and L. Vogel 2008. Distribution and growth reconsidered - empirical results for six OECD countries, Cambridge Journal of Economics, 32: 479-511.

Keen, S. 1995 Finance and economic breakdown modelling Minsky's 'financial instability hypothesis,' Journal of Post Keynesian Economics, 17, pp. 607-635.

Kiefer, D, Rada, C, 2015. Profit maximizing goes global: the race to the bottom Cambridge Journal of Economics forthcoming

Lavoie, M. and M. Seccareccia. 2001. Minsky's financial Fragility Hypothesis: A Missing Macroeconomic Link? In P. Ferri and R. Bellofiore (Eds.), Financial Fragility and Investment in the Capitalist Economy: The Economic Legacy of Hyman Minsky, volume II. Cheltenham: Edward Elgar. 
Lotka, A.J., 1925. Elements of Physical Biology, Williams and Wilkins.

Michell, J., 2014. Speculation, financial fragility and stock-flow consistency, in The Great Recession and the contradictions of contemporary capitalism, R. Bellofiore and G. Vertova (eds.), Edward Elgar, forthcoming.

Minsky, Hyman, 1975 John Maynard Keynes, New York: Columbia University Press

Minsky, Hyman, 1986. Stabilizing an unstable economy. New Haven: Yale University Press

Mohun, S, and R. Veneziani 2008. Goodwin Cycles and the U.S. Economy 1948-2004. In:

Mathematical Economics and the Dynamics of Capitalism, ed. P. Flaschel and M. Landesmann.

Routledge, 2008. Chapter 6, pp.107-130

Naastepad, C.W.M., and S. Storm 2006/7. OECD demand regimes (1960-2000). Journal of PostKeynesian Economics, 29: 213-248.

Nolting, B, Paullet, J, Previte, J, 2008. Introducing a scavenger onto a predator prey model. Applied Mathematics E-Notes 8, 214-22

Onaran, Ö., Galanis, G. 2012. Wage-led and profit-led demand: a global mapping ILO Working Papers, Conditions of Work and Employment Series No. 40.

Shah, A. and Desai, M., 1981, Growth Cycles with Induced Technical Change, The Economic Journal , Vol. 91, No. 364 (Dec.) , pp. 1006-1010.

Sherman, H. 1979. A Marxist theory of the business cycle. Review of Radical Political Economics, 11, $1-23$.

Sherman, H. 1997. Theories of cyclical profit squeeze. Review of Radical Political Economics, 29, 139147.

Solow, R. M. 1990. Goodwin's growth cycle: reminiscence and rumination. In K. V. Velupillai (Ed.) Multisectoral Macrodynamics. London: Macmillan.

Stockhammer, E., Ö. Onaran and S. Ederer 2009. Functional income distribution and aggregate demand in the Euro area. Cambridge Journal of Economics: 33 (1): 139-159

Stockhammer, E, Stehrer, R, 2011. Goodwin or Kalecki in demand? Functional income distribution and aggregate demand in the short run. Review of Radical Political Economics 43(4), 506-522

Skott, P., 1989, Effective demand, class struggle and cyclical growth. International Economic Review, 30, 1 , pp. 231-247

Skott, P., 1994. On the Modeling of Systemic Financial Fragility. In: Dutt (ed.): New Directions in Analytical Political Economy. Aldershot: Edward Elgar.

Taylor, L, 2012. Growth cycles, asset prices and finance. Metroeconomica 63, 1: 40-63 
Veneziani, R. and Mohun, S., 2006, Structural stability and Goodwin's growth cycle, Structural Change and Economic Dynamics, 17, pp. 437-451.

Volterra, V., 1926 Variazioni e fluttuazioni del numero d'individui in specie animali conviventi, Mem. Accademia die Lincei, Roma, 2, 31--113

Van Lear, W. 1999. Profitability in business cycle theory and forecasting. Review of Radical Political Economics, 31, 46-60. 


\section{Appendix}

\section{A.0 Routh Hurwitz stability conditions for a three-dimensional system}

Given a three dimensional Jacobian of the form,

$I_{3 D}=\left[\begin{array}{lll}J_{11} & J_{12} & J_{13} \\ J_{21} & J_{22} & J_{23} \\ J_{31} & J_{32} & J_{33}\end{array}\right]$

The characteristic equation of this system is:

$q^{3}+a_{1} q^{2}+a_{2} q+a_{3}$

Where

$a_{1}=-\operatorname{Tr}\left(J_{3 D}\right)=-\left(J_{11}+J_{22}+J_{33}\right)$

$$
a_{2}=\text { sum of all principal second-order minors of } I_{3 D}
$$

$=\left|\begin{array}{ll}J_{11} & J_{12} \\ J_{21} & J_{22}\end{array}\right|+\left|\begin{array}{ll}J_{11} & J_{13} \\ J_{31} & J_{33}\end{array}\right|+\left|\begin{array}{ll}J_{22} & J_{23} \\ J_{32} & J_{33}\end{array}\right|$

$a_{3}=-\operatorname{Det}\left(J_{3 D}\right)$

For this system to be stable, the following must hold:

$a_{1}, a_{2}, a_{3}>0$

$$
b=a_{1} a_{2}-a_{3}>0
$$

In the special case that,

$b=0$

the system is undergoing a Hopf bifurcation and a limit cycle is possible

\section{A.1 Stability analysis for extended Minsky model with reserve army mechanism}

The model is comprised of equations (3), (4) and (5), reproduced here for ease of exposition.

$\vec{f}=f(-1+p y)$

$\dot{y}=y(1-f)$ 
$\dot{w}=w(-c+r y-w)$

The non-zero steady state of the system occurs where,

$f^{*}=1, y^{*}=\frac{1}{p}, w^{*}=\frac{r}{p}-c$

The Jacobian of the system is,

$I=\left[\begin{array}{ccc}-1+p y & p f & 0 \\ -y & 1-f & 0 \\ 0 & r w & -c+r y-2 w\end{array}\right]$

Evaluated at the non-zero steady state,

$I^{*}=\left[\begin{array}{ccc}0 & p f^{*} & 0 \\ -y^{*} & 0 & y^{*} \\ 0 & r w^{*} & -w^{*}\end{array}\right]$

The Routh-Hurwitz conditions specified in Appendix A.0 can be calculated as follows,

$a_{1}=-\left(0+0-w^{*}\right)=w^{*}$

$a_{2}=\left(0--\left(p f^{*} y^{*}\right)\right)+(0-0)+(0-0)=1$

$a_{3}=-\left(-p f^{*}\left(-\frac{1}{p} \cdot-w^{*}\right)\right)=w^{*}$

$b=a_{1} a_{2}-a_{3}=0$

The system is thus stable and can generate limit cycles in the case that $w^{*}>0$ and unstable otherwise. The condition $w^{*}>0$ is fulfilled when $p<c / r$.

A.2 Extended Minsky model with reserve army mechanism without self-stabilising effect in wage share

In the case that equation (5) in the above system is replaced with equation (2),

$\dot{w}=w(-c+r y)$

the assumption of a self-stabilising wage-share is removed. In this case the condition for $\mathbb{W}=0$ is altered to the following:

$y_{0}=\frac{c}{r}$ 
Since we already have the condition, $y_{0}=\frac{1}{p}$, there can only be a steady state in all three variables in the case that $\frac{1}{p}=\frac{c}{r}$. In this case closed orbits are obtained in both $(f, y)$ space and $(y, w)$ space. While closed orbits in $(f, y)$ space will be generated regardless of the values of $p, c$ and $r$, the behavior in $(w, y)$ space will depend on the sign of $w_{0}$ :

If $\frac{1}{p}=\frac{c}{r}$ then closed orbits in $(y, w)$ space.

If $\frac{1}{p}>\frac{c}{r}$ then $w$ is unstable: exploding cycles in $(y, w)$ space are generated (with fixed amplitude of y)

If $\frac{1}{p}<\frac{c}{r}$ then $w$ converges on 0 , so imploding oscillations in $(y, w)$ space are generated and $w$ converges on zero (and $y$ oscillates at fixed amplitude).

The results of simulating this system in the case that $\frac{1}{p}<\frac{0}{r}$ is shown in Figure 7 
(a)

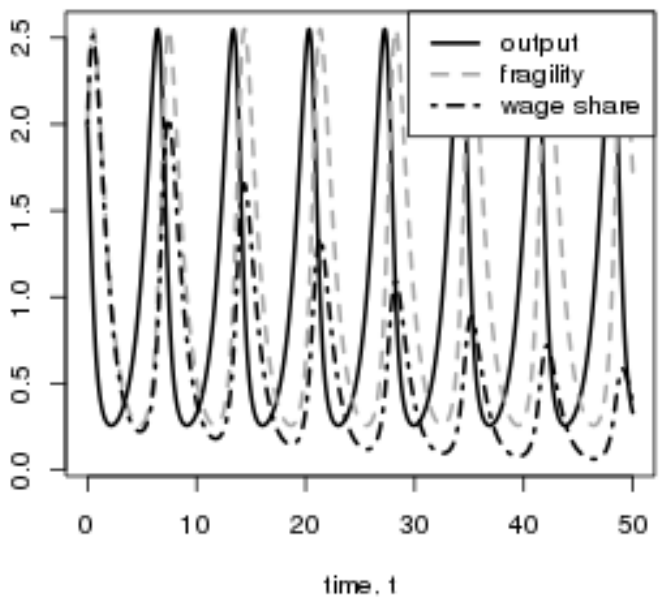

(c)

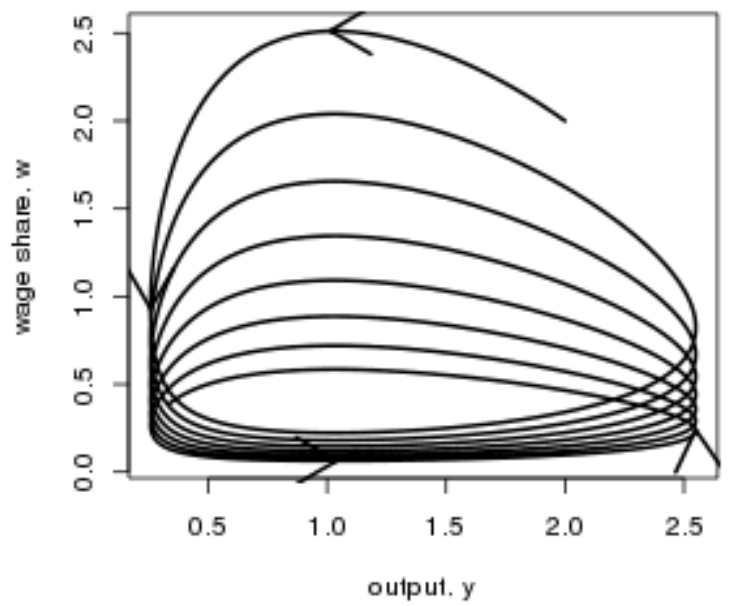

(b)

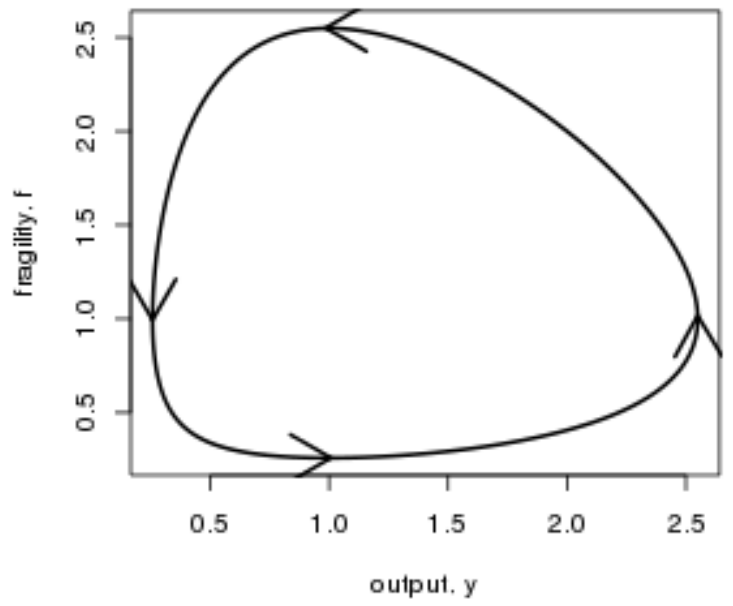

(d)

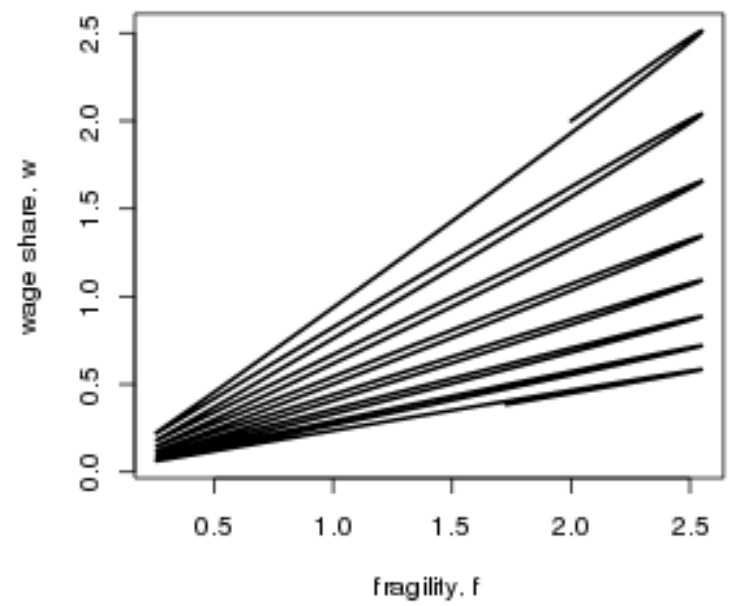

Figure 7 Extended Minsky model with reserve army mechanism and no self-stabilising wage effect

\section{A.3 Extended Minsky model with reserve army mechanism and wage-led demand}

If we take the system analysed in Appendix A.1, and replace equation (4) with (4'),

$$
\dot{y}=y(1-f+s w)
$$

We obtain the augmented Minsky system with reserve army mechanism and wage-led demand. In this case, the Routh-Hurwitz conditions become the following: 


$$
\begin{aligned}
& a_{1}=w_{0} \\
& a_{2}=1+s w_{0}\left(1-\frac{r}{p}\right) \\
& a_{3}=w_{0}\left(1+s w_{0}\right) \\
& b=w_{0}\left(f_{0}-\frac{s r w_{0}}{p}\right)-f_{0} w_{0} \\
& =-\frac{s r w_{0}}{p}
\end{aligned}
$$

The non-zero fixed point cannot be stable since $a_{1}$ and $b$ cannot simultaneously be positive. If $s>0$ then if $\frac{1}{p}>\frac{c}{r}$, so that $w_{0}>0$ then $b<0$. In this case, the system is unstable, and generates explosive cycles in all three variables. Nonetheless, the cycles in $(y, w)$ space are still anti-clockwise, thus generating the pseudo-Goodwin cycle.

\section{A.4 Non-linear models bounded with $(0,1)$ range}

The linear models presented in the main text generate trajectories in which no bounds are placed on variables. In particular, the wage share takes values that may exceed unity. Desai et. al (2006) note that this problem also affects Goodwin's original model and demonstrate how it may be overcome by replacing the linear Lotka-Volterra equations with non-linear versions.

Along similar lines, this section of the Appendix presents modified versions of the models presented in the main text which are bounded to the $(0,1)$ range in all variables.

\section{Simplified Goodwin Model}

Our simplified Goodwin model is given by the following pair of equations.

$\dot{y}=y(1-w)$

$\dot{w}=w(-c+r y)$

As is clear from Figure 2, this generates trajectories in which variables exceed unity. These equations can be replaced by the following pair of non-linear equations,

$$
\begin{aligned}
& \dot{y}=y(a+p \ln (1-w)) \\
& \dot{w}=w\left(-c+r y^{-1}\right)
\end{aligned}
$$


This system generates trajectories in which both $y$ and $w$ are confined to the range $(0,1) \cdot{ }^{8}$ See Desai et. al (2006) for a proof and further discussion of the assumptions underlying the functional specifications.

\section{Augmented Minsky Model}

In the case that the wage share is not part of the mechanism generating the cycle in $y$, it can be bounded to the $(0,1)$ range more simply by modifying the specification of the logistic term. Equation (5) can be replaced with the following:

$\dot{w}=w(-c+r y)(1-w)$

This equation specifies that the growth rate of the wage share is determined by the level of output but is constrained to remain less than one. In this model, if $\frac{1}{p}-\frac{c}{r}$ is non-zero, the wage-share either converges on 0 or 1 , depending on the sign of the expression. The result of simulating the system of Equations (3), (4) and (5a) with parameter values $c=1, p=0.95$ and $r=1.05$, is shown in Figure 8 .

If this system is augmented to include a wage-led demand effect by replacing Equation (4) with Equation (4a), the system generates limit cycles in $(y, f)$ space: as $w$ converges to either the upper or lower bound, $y$ and $f$ converge to steady undamped oscillations.

\footnotetext{
${ }^{8}$ Since Goodwin assumes constant labour productivity, $y$ can either represent output, such that $y=1$ is the full employment level of output, or can represent the employment rate directly.
} 


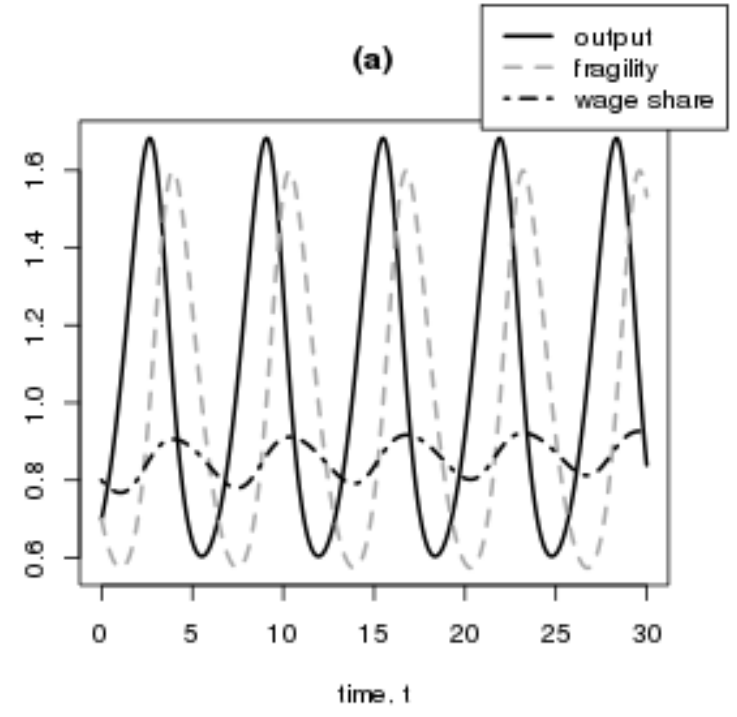

(c)

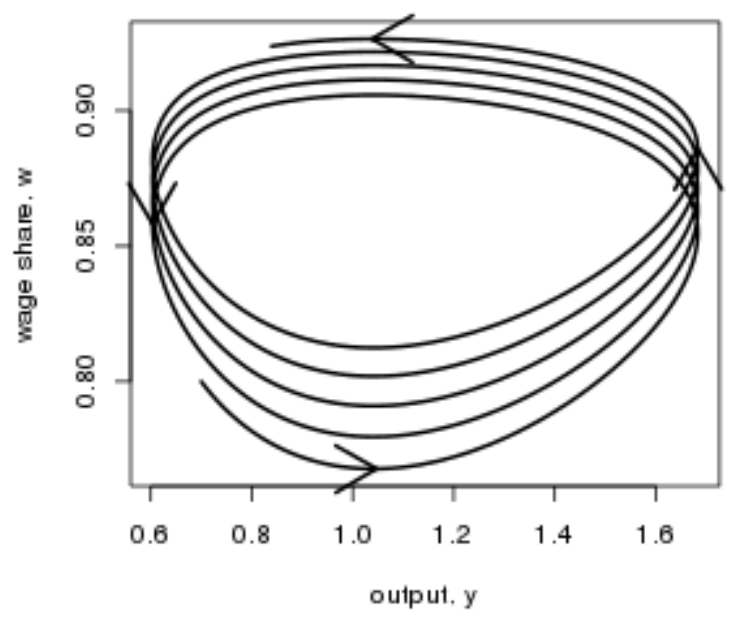

(b)

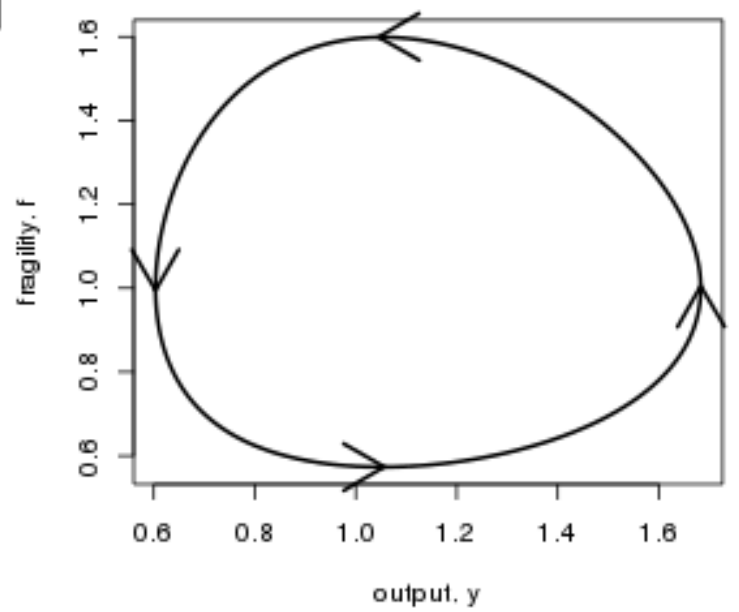

(d)

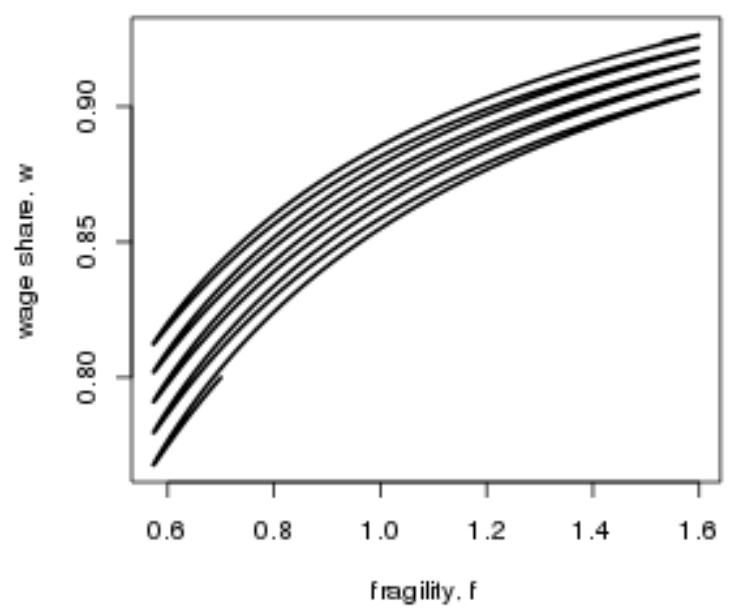

Figure 8 Augmented Minsky model with reserve army mechanism and bounded logistic wage share 